\title{
Aortic root surgery with circulatory arrest: Predictors of prolonged postoperative hospital stay
}

\author{
Ourania Preventza, MD, ${ }^{\mathrm{a}, \mathrm{b}}$ Joseph S. Coselli, MD, ${ }^{\mathrm{a}, \mathrm{b}}$ Andrea Garcia, MD, ${ }^{\mathrm{a}}$ Shahab Akvan, MD, ${ }^{\mathrm{a}}$ \\ Sarang Kashyap, MD, ${ }^{a}$ Katherine H. Simpson, MS, ${ }^{c}$ Matt D. Price, MD, ${ }^{a}$ Kim I. de la Cruz, MD, ${ }^{a}$ \\ Konstantinos Spiliotopoulos, MD, PhD, FETCS, ${ }^{\mathrm{a}, \mathrm{b}}$ Lorraine D. Cornwell, MD, ${ }^{\mathrm{a}, \mathrm{c}}$ \\ Faisal G. Bakaeen, MD, ${ }^{\mathrm{a}, \mathrm{b}, \mathrm{c}}$ Shuab Omer, MD, ${ }^{\mathrm{a}, \mathrm{c}}$ and Denton A. Cooley, MD ${ }^{\mathrm{b}}$
}

\section{ABSTRACT}

Objective: Little is known about the outcomes of aortic root operations that involve inducing hypothermic circulatory arrest for relatively extensive proximal aortic surgery. We attempted to identify predictors of postoperative hospital length of stay (LOS) and factors that affect postoperative recovery.

Methods: During 2006-2014, 247 of 265 patients (93.2\%) with disease extending into the aortic arch survived aortic root operations (206 elective, 41 urgent/emergent) in which hypothermic circulatory arrest with moderate hypothermia was used. Stepwise multivariate regression analysis was performed to identify predictors of LOS (as a continuous variable) and prolonged LOS (defined as LOS $>9$ days, the median for the cohort). By this definition, 111 patients $(45 \%)$ had prolonged LOS and $136(55 \%)$ did not.

Results: Preoperative factors that independently predicted longer LOS in the entire cohort included age $(P=.0014)$, redo sternotomy $(P=.0047)$, and intraoperative packed red blood cell (PRBC) transfusion $(P=.0007)$. Redo sternotomy and intraoperative PRBC transfusion also predicted longer LOS in 3 subgroup analyses: one of elective cases, one from which total arch replacement procedures were excluded, and one limited to patients who were discharged home. Age predicted longer LOS in the non-total arch (hemiarch) replacement patients. Ventilator support $>48$ hours $(P<.0001)$ was associated with longer LOS. Elective aortic valve-sparing root replacement predicted a shorter LOS than valve replacement in multivariate regression analysis $(P=.028)$.

Conclusions: In patients undergoing aortic root surgery with hypothermic circulatory arrest for disease extending into the aortic arch, reducing intraoperative PRBC transfusion except when absolutely necessary may reduce postoperative LOS and expedite recovery. Performing aortic valve-sparing root replacement, when feasible, may also reduce LOS. (J Thorac Cardiovasc Surg 2017;153:511-8)

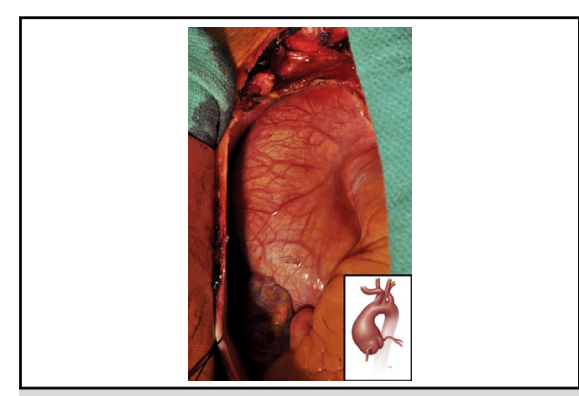

Shorter postoperative LOS is feasible after aortic root surgery with circulatory arrest.

\section{Central Message}

Useful strategies for improving recovery and decreasing postoperative length of stay after aortic root surgery with hypothermic circulatory arres may include blood conservation, aortic valve-sparing root replacement, and shortening postoperative ventilator support.

\section{Perspective}

Postoperative length of stay (LOS) not only has financial implications but also can affect patients' functional status Although some factors that can prolong LOS are not easily assessed in a retrospective study, we associated age, redo sternotomy, intraoperative packed red blood cell transfusion, and prolonged ventilator support with longer LOS, whereas aortic valve-sparing root replacement, when feasible, may reduce LOS.

See Editorial Commentary page 519.

See Editorial page 509.

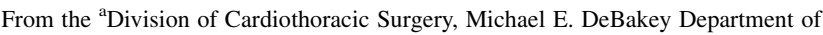
Surgery, Baylor College of Medicine; ${ }^{b}$ Department of Cardiovascular Surgery, Texas Heart Institute; and ${ }^{c}$ Division of Cardiothoracic Surgery, Michael E. DeBakey Veterans Affairs Medical Center, Houston, Tex.

Read at the 96th Annual Meeting of The American Association for Thoracic Surgery, Baltimore, Maryland, May 14-18, 2016.

Received for publication May 5, 2016; revisions received Sept 30, 2016; accepted for publication Oct 7, 2016; available ahead of print Dec 10, 2016

Address for reprints: Ourania Preventza, MD, BCM 390, One Baylor Plaza, Houston,

TX 77030 (E-mail: opsmile01@aol.com).

$0022-5223 / \$ 36.00$

Copyright (c) 2016 by The American Association for Thoracic Surgery

http://dx.doi.org/10.1016/j.jtcvs.2016.10.090
}

Postoperative length of stay (LOS) not only has financial implications but also can affect patients' functional status. As surgeons, we may have little control over preoperative

Scanning this QR code will take you to the article title page. To view the AATS 2016 Webcast, see the URL next to the video thumbnail.

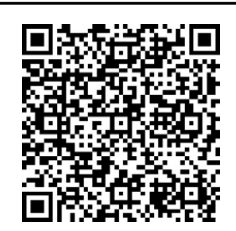




\section{Abbreviations and Acronyms \\ $\mathrm{ACP}=$ antegrade cerebral perfusion \\ AVSRR $=$ aortic valve-sparing root replacement \\ $\mathrm{CPB}=$ cardiopulmonary bypass \\ LOS = length of stay \\ PRBC $=$ packed red blood cells \\ TAR $=$ total arch replacement}

LOS, but we potentially can have significant influence over the postsurgical LOS in patients who undergo major aortic operations.

Even though the results of aortic root surgery are well documented in large series, ${ }^{1-9}$ LOS data often are not provided. In addition, much less is known about the outcomes of aortic root operations in patients whose proximal ascending aortic disease necessitates the use of hypothermic circulatory arrest during the procedure.

Thus, we analyzed preoperative and intraoperative factors that may affect recovery in patients who had aortic root surgery in combination with a hemiarch or total arch operation under moderate hypothermia, and we sought to identify predictors of postoperative hospital LOS after such procedures. Our purpose was to determine whether there is anything that we as clinical surgeons can do, intraoperatively or postoperatively, to reduce the postoperative LOS in these patients.

\section{MATERIALS AND METHODS}

During a recent 8-year period (April 2006-December 2014), 265 consecutive patients underwent aortic root surgery with hypothermic circulatory arrest under moderate hypothermia $\left(20.1^{\circ} \mathrm{C}-28^{\circ} \mathrm{C}\right)$. The 247 patients $(93.2 \%)$ who survived the operation were the focus of our analysis. Approval was obtained from the institutional review board at Baylor College of Medicine, and data were collected from a prospectively maintained database. The median hospital LOS of the cohort was calculated (median $\operatorname{LOS}=9$ days), and prolonged LOS was defined as LOS $>9$ days. The preoperative, intraoperative, and postoperative variables used in this study have been defined previously. ${ }^{10}$ Antegrade cerebral perfusion (ACP) time was the time for which the patient received ACP. Circulatory arrest time was defined as the total period of circulatory arrest with or without ACP. Myocardial ischemia time was the period from the initiation of circulatory arrest or crossclamp placement until clamp removal, and cardiopulmonary bypass (CPB) time was the period of CPB without circulatory arrest or ACP. Patients received mechanical roots $(n=105)$ or bioprosthetic roots $(\mathrm{n}=92)$ or underwent aortic valve-sparing root replacement (AVSRR) procedures $(n=50)$. Patient characteristics and demographics are shown in Table 1.

\section{Intraoperative Technique and Details}

Open distal anastomosis. Intraoperative transesophageal echocardiography and near-infrared spectroscopy were used in all patients. All cases required circulatory arrest and were performed under moderate hypothermia (with a target nasopharyngeal temperature of $20.1{ }^{\circ} \mathrm{C}-28^{\circ} \mathrm{C}$ ). All patients except 2 received ACP. In these 2 patients, pure circulatory arrest times were 11 and 6 minutes, respectively. For more complicated distal anastomoses, we used colder temperatures. The mean lowest temperature for the cohort was $23.2 \pm 1.82^{\circ} \mathrm{C}$ standard error.

During the cooling period, in cases in which the aorta could be crossclamped (we do not crossclamp the aorta in cases of acute dissection), the proximal aortic root was dissected to the level of the aortic sinuses. We continued with the dissection of the aortic root until the target temperature was reached. Then, low-flow ACP (10-15 mL/kg/min) was initiated, first unilaterally and then bilaterally. The ascending aorta was opened and inspected, the diseased tissue was excised, and a graft was sewn to the distal aorta. Two reconstruction techniques were used for the total arch replacement (TAR): the island patch configuration with implantation of 2 or all 3 head vessels, and the Y-graft aortic arch configuration with a prefabricated or custom-made bifurcated (Y), trifurcated (double-Y), or single graft (Vascutek Terumo, Renfrewshire, Scotland). When the distal anastomosis was complete, CPB was resumed at full flow, and the graft was crossclamped. Aortic root procedure. After the root was dissected to the level of the sinuses and the ventriculo-aortic junction, the ascending aorta was opened and cardioplegia was administered antegrade, directly into the coronary ostia. Myocardial protection during the entire operation was achieved with retrograde and antegrade cardioplegia. The nasopharyngeal temperature was slowly increased to $28^{\circ} \mathrm{C}$ to $30^{\circ} \mathrm{C}$. The coronary artery origins were mobilized. The aortic cusps were inspected, as were the sinuses. If we considered the valve to be salvageable, we proceeded with AVSRR by the David reimplantation procedure.

We have described our technique of AVSRR previously. ${ }^{11}$ In the 50 AVSRRs performed in the current series, we exclusively used the Valsalva nonvalved graft with the prefabricated skirt that mimics the curved sinus segment (Vascutek Terumo). If the valve was not salvageable, then we used a mechanical root (composite St Jude Valsalva-valved graft; Vascutek Terumo) or a bioprosthetic root (mainly the Medtronic Freestyle [Medtronic, Inc, Minneapolis, Minn], although a few patients received a prefabricated bioroot). For the mechanical root, pledgeted sutures were placed in the aortic annulus, and a running 2-0 Prolene suture was used for the placement of the Medtronic Freestyle root. Mobilizing the coronary ostia allowed reimplantation of the coronary arteries in the opening cut in the root graft for the mechanical valved conduit and into the porcine root for the bioroot. Further intraoperative details, intraoperative times, and concomitant procedures are shown in Table 2.

Follow-up. Among the 247 patients who survived the operation, 206 $(83.4 \%)$ were discharged home $(n=130[63.1 \%] \leq 9$ days, $n=76$ [36.9\%] $>9$ days). Thirty-three patients $(13.4 \%)$ went to an extended care facility, and $8(3.2 \%)$ went to a rehabilitation center. Among the 41 patients who were not discharged home, $35(85.4 \%)$ had prolonged LOS ( $>9$ days), and $6(14.6 \%)$ did not $(P<.0001)$.

\section{Statistical Analysis}

Our analysis included 20 preoperative variables (serum creatinine level, atrial fibrillation, age, sex, myocardial infarction, hypertension, diabetes, redo sternotomy, previous cardiac surgery, current or past smoking, previous coronary artery bypass grafting, congestive heart failure, renal disease, chronic obstructive pulmonary disease, neurologic deficit, stroke, intubation, coronary artery disease, coronary event, and ejection fraction), 13 intraoperative variables (emergency operation, TAR, frozen elephant trunk procedure, AVSRR, concomitant coronary artery bypass grafting, moderate hypothermia, CPB time, cardiac ischemia time, total circulatory arrest time, ACP, and transfusion of packed red blood cells [PRBC], fresh-frozen plasma, and platelets), and 10 postoperative variables (atrial fibrillation, ventilator support $>48$ hours, reoperation for bleeding, wound complications, any renal failure, permanent renal failure necessitating hemodialysis, deep vein thrombosis, myocardial infarction, stroke, and tracheostomy) to determine which factors predicted greater LOS. A stepwise regression analysis model determined which variables predicted continuous LOS, which contained the $\log$ transformation to reduce the skewness of the data. Residual analysis performed on the log transformed LOS showed 
TABLE 1. Preoperative characteristics

\begin{tabular}{|c|c|c|c|c|}
\hline Preoperative characteristics & Overall, $\mathbf{n}=\mathbf{2 4 7}$ & LOS $\leq \mathbf{9} \mathrm{d}, \mathbf{n}=136$ & LOS $>9 \mathrm{~d}, \mathrm{n}=111$ & $P$ value \\
\hline Median age (IQR), y & $55(43-63)$ & $52(41-60)$ & $58(49-67)$ & .0004 \\
\hline Age $>70 y$ & $29(11.7)$ & $9(31.0)$ & $20(69.0)$ & .0056 \\
\hline Male sex & $210(85.0)$ & $124(59.0)$ & $86(41.0)$ & .0027 \\
\hline Redo sternotomy & $65(26.3)$ & $19(29.2)$ & $46(70.8)$ & $<.0001$ \\
\hline Smoking (current or previous) & $95(38.5)$ & $50(52.6)$ & $45(47.4)$ & .54 \\
\hline Previous $\mathrm{CABG}$ & $5(2.0)$ & $1(20.0)$ & $4(80.0)$ & .18 \\
\hline Hypertension & $188(76.1)$ & 97 (51.6) & $91(48.4)$ & .051 \\
\hline COPD & $75(30.4)$ & $35(47.0)$ & $40(53.0)$ & .08 \\
\hline Preoperative cardiac disease unrelated to aorta* & $69(27.9)$ & $30(43.5)$ & $39(56.5)$ & .023 \\
\hline Previous proximal aortic dissection & $25(10.1)$ & $9(36.0)$ & $16(64.0)$ & .043 \\
\hline Congestive heart failure & $30(12.2)$ & $9(30.0)$ & $21(70.0)$ & .0032 \\
\hline Renal dysfunction & $22(8.9)$ & $6(27.3)$ & $16(72.7)$ & .006 \\
\hline History of stroke or TIA & $25(10.1)$ & $12(48.0)$ & $13(52.0)$ & .45 \\
\hline Diabetes mellitus & $17(6.9)$ & $8(47.1)$ & $9(52.9)$ & .49 \\
\hline
\end{tabular}

Data reported as n (\%) unless otherwise noted. $L O S$, Length of stay; $I Q R$, interquartile range; $C A B G$, coronary artery bypass grafting; $C O P D$, chronic obstructive pulmonary disease; TIA, transient ischemic attack. *Myocardial infarction, coronary artery disease, or previous procedure for cardiac disease (eg, CABG, percutaneous transluminal coronary angioplasty, pacemaker implantation).

an improvement in the model versus use of the nontransformed data for both the kernel density plot and the normal quantile plot. The R-squared value for the $\log$ transformed LOS is 0.63 , intercept $=1.81$ (Table 3 , continuous LOS with $\log$ transformation $P$ value). A stepwise nominal logistic regression was used to model the variables that predicted prolonged LOS ( $>9$ days). Before the models were run, multicollinearity was checked with regression analysis. The Hosmer-Lemeshow $P$ value was .59 , Cindex $=0.89$ (Table 3, LOS $>9$ days).

Four subgroup analyses were performed. In the first, we excluded all patients who underwent TAR $(n=26)$. We reran the logistic regression model to determine whether the same risk factors independently predicted greater LOS in this subgroup as in the full cohort. In the second subgroup analysis, we included only the elective cases $(n=206)$; in the third, we examined only the patients who were discharged home $(\mathrm{n}=206)$; and in the fourth, we excluded all of the redo patients $(n=182)$.

In addition, because we considered the type of root procedure to be a variable of interest, we attempted to compare the outcomes of AVSRR and non-AVSRR patients. We propensity-matched elective patients from these 2 groups by using a multivariate stepwise logistic regression model in which AVSRR (yes/no) was used as the dependent variable and the other preoperative and intraoperative variables were used as independent variables. The resulting model had a C-index of 0.73 . We then used a SAS macro to propensity-match each AVSRR patient to a non-AVSRR patient however, this matching procedure produced only 46 matched pairs, and we decided that because this sample size would not afford adequate statistical power to detect differences in outcomes, we needed to abort this part of the analysis.

Statistical analyses were performed with SAS version 9.1 (SAS Institute, Inc, Cary, NC). Statistical significance was determined by $P<.05$.

\section{RESULTS}

For the 247 patients included in the analysis, short-term outcomes are shown in Table 4, and the results of

TABLE 2. Operative variables

\begin{tabular}{|c|c|c|c|c|}
\hline Operative variables & Overall, $\mathbf{n}=\mathbf{2 4 7}$ & LOS $\leq \mathbf{9}$ d, $n=136$ & LOS $>9 \mathrm{~d}, \mathrm{n}=111$ & $P$ value \\
\hline Urgency of operation & & & & .0092 \\
\hline Elective & $206(83.4)$ & $121(89.0)$ & $85(76.6)$ & \\
\hline Emergent/urgent & $41(16.6)$ & $15(11.0)$ & $26(23.4)$ & \\
\hline \multicolumn{5}{|l|}{ Concomitant procedures } \\
\hline Hemiarch & $221(89.5)$ & $131(96.3)$ & $90(81.1)$ & .0001 \\
\hline Total arch replacement & $26(10.5)$ & $5(3.7)$ & $21(18.9)$ & .0001 \\
\hline Coronary artery bypass & $35(14.2)$ & $12(8.8)$ & $23(20.7)$ & .0077 \\
\hline Others* & $25(10.1)$ & $13(9.6)$ & $12(10.8)$ & .75 \\
\hline AVSRR & $50(20.2)$ & $35(25.7)$ & $15(13.5)$ & .017 \\
\hline Intraoperative $\mathrm{PRBC}$ transfusion & $113(45.8)$ & $37(27.2)$ & $76(68.5)$ & $<.0001$ \\
\hline Intraoperative FFP transfusion & $153(61.9)$ & $70(51.5)$ & $83(74.8)$ & .0002 \\
\hline \multicolumn{5}{|l|}{ Operative times, $\min$} \\
\hline CPB time & $157(132-194)$ & $153(129-188.5)$ & $165(137-214)$ & .046 \\
\hline Myocardial ischemia time & $117(94-139)$ & $111.5(93.5-136.5)$ & $119(97-153)$ & .16 \\
\hline ACP time & $19(15-27)$ & $17(15-24)$ & $21(16-35)$ & .0007 \\
\hline Circulatory arrest time & $19(15-28)$ & $17(15-24)$ & $22(17-35)$ & $<.0001$ \\
\hline
\end{tabular}

Data reported as n (\%) for categorical variables and median (interquartile range) for continuous variables. LOS, Length of stay; AVSRR, aortic valve-sparing root replacement; $P R B C$, packed red blood cells; $F F P$, fresh-frozen plasma; $C P B$, cardiopulmonary bypass; $A C P$, antegrade cerebral perfusion. *Tricuspid valve, mitral valve, or patent foramen ovale repair. 
TABLE 3. Factors associated with postoperative hospital LOS in multivariate regression (continuous LOS with a log transformation) and logistic regression analysis $(\operatorname{LOS}>9)$, all patients $(n=247)$

\begin{tabular}{|c|c|c|c|c|}
\hline Variable & $\begin{array}{c}\text { Continuous LOS } \\
\text { (with a } \log \text { transformation) } \\
P \text { value } \\
\end{array}$ & $\begin{array}{c}\text { Parameter } \\
\text { estimate } \pm \text { standard } \\
\text { error }\end{array}$ & $\begin{array}{l}\text { LOS }>9 \\
P \text { value }\end{array}$ & OR $(95 \%$ CI $)$ \\
\hline \multicolumn{5}{|l|}{ Preoperative } \\
\hline Age, y & .0014 & $0.0054 \pm 0.0017$ & .0034 & $1.05(1.02-1.08)$ \\
\hline Female & - & - & .027 & $3.38(1.15-9.93)$ \\
\hline Redo sternotomy & .0047 & $0.16 \pm 0.058$ & .014 & $3.04(1.26-7.37)$ \\
\hline Smoking (current or previous) & - & - & .0089 & $2.75(1.29-5.88)$ \\
\hline Preoperative cardiac disease unrelated to aorta* & .041 & $0.11 \pm 0.053$ & - & - \\
\hline \multicolumn{5}{|l|}{ Intraoperative } \\
\hline AVSRR & $.028 \dagger$ & $-0.13 \pm 0.057$ & - & - \\
\hline PRBC transfusion & .0007 & $0.17 \pm 0.049$ & .0035 & $3.13(1.46-6.74)$ \\
\hline Circulatory arrest time & - & - & .023 & $1.03(1.00-1.05)$ \\
\hline \multicolumn{5}{|l|}{ Postoperative } \\
\hline Ventilation $>48 \mathrm{~h}$ & $<.0001$ & $0.58 \pm 0.071$ & $<.0001$ & 25.35 (6.47-99.36) \\
\hline Tracheostomy & .0001 & $0.40 \pm 0.10$ & - & - \\
\hline Atrial fibrillation & - & - & .046 & $2.35(1.02-5.42)$ \\
\hline Acute renal insufficiency & .0015 & $0.25 \pm 0.078$ & .013 & 15.57 (1.79-135.62) \\
\hline
\end{tabular}

LOS, Length of stay; OR, odds ratio; CI, confidence interval; AVSRR, aortic valve-sparing root replacement; PRBC, packed red blood cells. *Preop cardiac unrelated to aorta refers to myocardial infarction, coronary artery disease, or previous procedure for cardiac disease (eg, CABG, percutaneous transluminal coronary angioplasty, pacemaker implantation). †AVSRR was associated with shorter LOS.

multivariate regression analysis (for continuous LOS) and logistic regression analysis (for LOS $>9$ days) are shown in Table 3. The multivariate regression analysis (for continuous LOS) identified the following factors as independent predictors of longer LOS: age $(P=.0014)$, redo sternotomy $(P=.0047)$, preoperative cardiac disease unrelated to aorta $(P=.041)$, intraoperative PRBC transfusion $(P=.0007)$, ventilatory support for more than 48 hours $(P<.0001)$, and postoperative renal insufficiency $(P=.0015)$. In contrast, AVSRR predicted shorter LOS $(P=.028)$. Interestingly, in 3 of the logistic regression analyses of subgroups-the one from which TAR patients were excluded $(n=221)$, the one for elective cases only $(n=206)$, and the one for only those patients who were discharged home $(\mathrm{n}=206)$ —produced similar results (Table 5). In the fourth subgroup analysis, which included only the non-redo patients $(\mathrm{n}=182)$ (Table 6), LOS was strongly associated with age and female sex, and $73 \%$ of the women in that group required intraoperative PRBP transfusion.

Because prolonged (ie, $>48$ hours) ventilator support was a significant predictor of prolonged LOS, we tested for factors that might independently predict it. We found 4 such predictors: intraoperative PRBC transfusion $(P=.0014)$, congestive heart failure $(P=.0069)$, TAR $(P=.0011)$, and emergent status $(P=.0084)$.

With regard to the type of root procedure, AVSRR was associated with prolonged LOS in the univariate analysis $(P=.017)$, and it was an independent predictor of shorter LOS in the multivariate regression analysis $(P=.028)$.

TABLE 4. Short-term outcomes

\begin{tabular}{|c|c|c|c|c|}
\hline Outcome variable & Overall, $\mathrm{n}=\mathbf{2 4 7}$ & $\operatorname{LOS} \leq \mathbf{9} d, n=136$ & $\operatorname{LOS}>9 \mathrm{~d}, \mathbf{n}=111$ & $P$ value \\
\hline Stroke & $4(1.6)$ & $1(0.7)$ & $3(2.7)$ & .33 \\
\hline Permanent stroke & $2(0.8)$ & 0 & $2(1.8)$ & .20 \\
\hline Paraparesis & $1(0.4)$ & 0 & $1(0.9)$ & .45 \\
\hline Any neurologic event* & $5(2.0)$ & $1(0.7)$ & $4(3.6)$ & .18 \\
\hline Permanent neurologic deficit* & $2(0.8)$ & 0 & $2(1.8)$ & .20 \\
\hline Ventilation $>48 \mathrm{~h}$ & $53(21.5)$ & $3(2.2)$ & $50(45.1)$ & $<.0001$ \\
\hline Tracheostomy & $20(8.1)$ & 0 & $20(18.0)$ & $<.0001$ \\
\hline Acute renal insufficiency & $26(10.5)$ & $1(0.7)$ & $25(22.5)$ & $<.0001$ \\
\hline Reoperation for bleeding & $18(7.3)$ & $3(2.2)$ & $15(13.5)$ & .0007 \\
\hline Pericardial window & $16(6.5)$ & $3(2.2)$ & $13(11.7)$ & .0025 \\
\hline Atrial fibrillation & $66(26.7)$ & $26(19.1)$ & $40(36.0)$ & .0028 \\
\hline ICU LOS, $d$ & $2(2-6)$ & $2(1-3)$ & $6(2-18)$ & $<.0001$ \\
\hline Postoperative LOS, d & $9(7-16)$ & $7(7-8)$ & $17(11-24)$ & $\mathrm{n} / \mathrm{a}$ \\
\hline
\end{tabular}

Data reported as n (\%) for categorical variables and median (interquartile range) for continuous variables. $L O S$, Length of stay; ICU, intensive care unit; $n / a$, not available. *Stroke, paraparesis, paraplegia. 
TABLE 5. Predictors of prolonged postoperative hospital LOS ( $>9 \mathrm{~d})$ in subgroup multivariate logistic regression analyses

\begin{tabular}{|c|c|c|c|c|c|c|}
\hline \multirow[b]{2}{*}{ Variable } & \multicolumn{2}{|c|}{$\begin{array}{l}\text { Elective-only patients, } \\
\mathbf{n}=\mathbf{2 0 6}\end{array}$} & \multicolumn{2}{|c|}{$\begin{array}{l}\text { Only non-TAR patients, } \\
\quad \mathbf{n}=\mathbf{2 2 1}\end{array}$} & \multicolumn{2}{|c|}{$\begin{array}{c}\text { Only patients discharged } \\
\text { home after surgery, } \mathbf{n}=\mathbf{2 0 6}\end{array}$} \\
\hline & $P$ value & OR $(95 \%$ CI $)$ & $P$ value & OR $(95 \%$ CI $)$ & $P$ value & OR $(95 \%$ CI $)$ \\
\hline \multicolumn{7}{|l|}{ Preoperative } \\
\hline Age, $y$ & & & .0035 & $1.03(1.00-1.06)$ & & \\
\hline Redo sternotomy & .0007 & $4.80(1.95-11.85)$ & .0004 & $6.44(2.30-17.98)$ & .010 & $3.16(1.31-7.60)$ \\
\hline Smoking (current or previous) & .015 & $2.82(1.23-6.50)$ & .0002 & $5.12(2.17-12.04)$ & .014 & $2.59(1.21-5.54)$ \\
\hline \multicolumn{7}{|l|}{ Intraoperative } \\
\hline PRBC transfusion & .0002 & $4.54(2.04-10.12)$ & .0001 & $4.90(2.19-10.96)$ & .001 & $4.43(2.07-9.48)$ \\
\hline \multicolumn{7}{|l|}{ Postoperative } \\
\hline Ventilation $>48 \mathrm{~h}$ & $<.0001$ & $21.00(4.80-91.94)$ & $<.0001$ & $60.32(11.40-319.03)$ & .0001 & $18.67(4.25-81.91)$ \\
\hline Atrial fibrillation & .014 & $2.91(1.24-6.82)$ & .023 & $2.73(1.15-6.48)$ & .0043 & 3.37 (1.46-7.77) \\
\hline
\end{tabular}

Hosmer-Lemeshow (HL) $P$ value for elective subgroup .66, C-index 0.87; HL $P$ value for non-TAR subgroup .99, C-index 0.89 ; and HL $P$ value for subgroup of patients discharged home $.71, \mathrm{C}$-index 0.84 . $O R$, Odds ratio; $C I$, confidence interval; TAR, total arch replacement; $P R B C$, packed red blood cells. $*$ Non-TAR $=$ hemiarch.

\section{DISCUSSION}

The modified Bentall aortic root operation, consisting of composite valved graft placement and coronary button reimplantation, has had superb early results and long-term durability. ${ }^{12,13}$ If there is associated dilation of the ascending aorta, this segment can be replaced concomitantly with the aortic root to prevent future aortic dissection. ${ }^{12}$ Few studies in the literature concentrate only on aortic root surgery that requires circulatory arrest. ${ }^{14}$ Rather, most reported large series of aortic root procedures consist chiefly of cases performed without circulatory arrest; cases performed with it are in the minority. $2,4,8,9,15$

The LOS has been used as a proxy for resource use and as an indicator of hospital performance. The present study focuses on predictors of LOS in consecutive patients who underwent aortic root surgery with circulatory arrest and survived the operation. Our median LOS (9 days) was longer than that reported by Malaisrie and colleagues, ${ }^{14}$ whose 177 patients all underwent concomitant aortic root surgery and hemiarch reconstruction and had a median LOS of 6 days. This discrepancy may be attributable to the fact that more than $10 \%$ of our patients (26/247) underwent TAR procedures; most of these patients stayed in hospital for longer than 9 days. In addition, TAR independently predicted prolonged pulmonary ventilator support $(P=.001)$, which was the strongest predictor of prolonged LOS.

Age and previous sternotomy were found to be associated with longer LOS in our study, both among all patients and in the subgroup analysis of the non-TAR patients. Among the elective patients and those who were discharged home, redo sternotomy remained an independent predictor of prolonged LOS, but age did not. In our cohort, the majority of the patients aged $\geq 70$ years had prolonged LOS. Gaudino and colleagues, ${ }^{15}$ in a cohort of 890 consecutive patients who underwent aortic root surgery (154 [17.3\%] with circulatory arrest) during a 17 -year period, did not model LOS but nonetheless showed that age and

TABLE 6. Predictors of prolonged postoperative hospital LOS ( $>9 \mathrm{~d})$ in subgroup multivariate logistic regression analyses for non-redo patients only

\begin{tabular}{|c|c|c|}
\hline \multirow[b]{2}{*}{ Variable } & \multicolumn{2}{|c|}{ Non-redo patients, $n=182$} \\
\hline & $P$ value & OR $(95 \%$ CI $)$ \\
\hline \multicolumn{3}{|l|}{ Preoperative } \\
\hline Age, y & .0006 & $1.06(1.03-1.10)$ \\
\hline Redo sternotomy & - & - \\
\hline Female & .0007 & $7.01(2.26-21.74)$ \\
\hline Hypertension & - & - \\
\hline Smoking (current or previous) & .018 & $2.78(1.19-6.49)$ \\
\hline Preoperative cardiac disease unrelated to aorta* & - & - \\
\hline \multicolumn{3}{|l|}{ Intraoperative } \\
\hline PRBC transfusion & - & - \\
\hline Circulatory arrest time, $\min$ & .0009 & $1.05(1.02-1.09)$ \\
\hline \multicolumn{3}{|l|}{ Postoperative } \\
\hline Ventilation $>48 \mathrm{~h}$ & $<.0001$ & $21.57(4.92-94.48)$ \\
\hline Acute renal insufficiency & .020 & $14.02(1.51-130.49)$ \\
\hline Atrial fibrillation & - & - \\
\hline
\end{tabular}


reoperation were associated with adverse in-hospital outcome. Stamou and colleagues, ${ }^{16}$ using the Society of Thoracic Surgeons database, analyzed data from 13,743 patients who underwent aortic root surgery only during a 6year period (2004-2010) and found that increasing age and redo sternotomy were associated with prolonged LOS $>14$ days. In another analysis of Society of Thoracic Surgeons data (from 2004 to 2009), of 45,894 cases of proximal aortic replacement, 4358 were classified as root plus arch cases. ${ }^{17}$ Among these cases, age $>70$ years and reoperation status were associated with adverse outcome. LOS was not modeled in this analysis. In another report, redo sternotomy was associated with the same LOS as first-time sternotomy. ${ }^{18}$

Blood transfusion has been associated with postoperative morbidity not only in routine cardiac surgical procedures but also in complex aortic surgery. ${ }^{19-21}$ In the present study, we showed that among all survivors, intraoperative PRBC transfusion was associated with prolonged pulmonary support, which had the most impact on patients' risk of prolonged LOS. In addition, intraoperative PRBC administration was directly and independently associated with increased LOS, which other studies have not found. ${ }^{19,21}$ Yaffee and colleagues, ${ }^{21}$ in their study of $132 \mathrm{pa}$ tients who underwent complex aortic surgery (the number of patients in whom circulatory arrest was used is not mentioned in their report) for treatment of aneurysm or dissection, associated the use of a blood-conservation strategy with longer hospital stays (10.8 \pm 9.6 days) than standard treatment $(7.9 \pm 4.9$ days, $P=.04)$. However, when the authors stratified the patients by surgical acuity and disease type, blood conservation was not associated with LOS. Chu and colleagues, ${ }^{19}$ in analyzing data from 189 patients who underwent aortic root and ascending aortic operations during a period of 5 years (again, the number of patients in whom circulatory arrest was used is not reported), found that blood conservation had no effect on LOS despite the diminished perioperative morbidity seen in the blood conservation strategy group.

With regard to the present study, one could argue that because the patients undergoing TAR received more PRBC transfusions than the hemiarch patients (as expected), and because most of the patients who underwent TAR stayed in the hospital for more than 9 days (the median for the entire cohort), the relationship between PRBC transfusion and LOS might be mediated entirely by TAR. However, in our subgroup analysis from which we excluded the patients undergoing TAR $(\mathrm{n}=26)$, PRBC transfusion continued to be independently associated with prolonged LOS, as well as ventilatory support exceeding 48 hours. Likewise, in our subgroup analyses of the elective cases only $(\mathrm{n}=206)$ and of the cases in which the patients were discharged home $(n=206)$, intraoperative PRBC transfusion was still associated with prolonged LOS. In addition, in our subgroup analysis of non-redo procedures, female sex was independently associated with prolonged LOS, whereas intraoperative PRBC transfusion was not. However, $73 \%$ of the female patients required intraoperative PRBC transfusion, suggesting a strong interaction between sex and PRBC in the non-redo subgroup.

Valve-sparing root surgery, pioneered by Tirone David, ${ }^{22}$ has shown excellent results when performed by experienced surgical groups. ${ }^{1,4,8,11,22}$ When feasible, it is considered a favorable alternative to valve replacement. ${ }^{16}$ Judicious expansion of the indications for aortic valve-sparing procedures is recommended by others. ${ }^{22}$ In our study, we found that AVSRR was associated with shorter LOS in the univariate analysis and that it was an independent predictor of shorter LOS in the full cohort. Because of the relatively small number of AVSRR and non-AVSRR patients who could be matched by propensity score, data from the matched patients were not analyzed.

This result agrees with others' findings. ${ }^{8}$ The shorter LOS of the AVSRR patients versus the non-AVSRR patients (ie, mechanical and bioprosthetic valve recipients) is not a total surprise, because AVSRR procedures are performed in stable, elective patients with fewer comorbidities than root-replacement patients have. Often, AVSRR patients are relatively young people with connective tissue disorders. Administering warfarin during the postoperative period appears to lengthen the postoperative LOS for patients with a mechanical root. In addition, although these data do not specifically capture hemodynamics and valve gradients, we strongly believe that the aortic valvesparing operation is superior to the Bentall procedure on both counts and that the valve-sparing approach favorably influences early recovery. Svensson and colleagues ${ }^{8}$ reported that, among 957 patients who underwent nonemergency root procedures during a 16-year period, 234 patients underwent circulatory arrest for arch surgery. Circulatory arrest was used less often in patients with valve-preserving root surgery. Although this report concentrates on survival and long-term durability for all $957 \mathrm{pa}-$ tients with root and concomitant ascending aortic surgery and not specifically on the patients with circulatory arrest, the authors found that patients with valve-preserving root surgery had shorter hospital stays than the patients who received allografts, bioroots, or mechanical roots.

In addition, our study suggests that previous or current smoking is associated with prolonged LOS. When we stratified patients into those with chronic obstructive pulmonary disease versus those without it, the patients with chronic obstructive pulmonary disease stayed in the hospital longer postoperatively (median LOS 10 days, interquartile range 8-21 vs median LOS 9, interquartile range 7-14; $P<.0001)$.

The main limitation of our study is its retrospective design, the inherent limitations of which make it difficult 
to accurately quantify the influence of various factors on prolonged LOS after surgery. In addition, blood product use is a complex parameter and was not recorded during the postoperative period. Preoperative hemoglobin levels were not recorded, either. Nevertheless, to our knowledge, this is one of the few studies, if not the only study, to focus on postoperative LOS in patients who require circulatory arrest for extensive ascending aortopathy and undergo aortic root surgery. Although we did not deal specifically absolute cost per se, we recognize that a reduction of postoperative LOS clearly represents a cost savings. Cost savings are variable, and marked differences are to be expected between private and academically affiliated hospitals, among regions of the United States, and certainly among international institutions. Regardless, a reduction of LOS represents a cost savings.

Prolonged LOS could have several interacting components. Developing interventions to reduce postoperative LOS and validating measures of recovery are imperative. Our findings suggest that age, previous or current smoking, redo sternotomy, intraoperative PRBC transfusion, and prolonged ventilator support affect recovery and lead to prolonged LOS, whereas AVSRR, when feasible, may reduce LOS. Although there is nothing to be done about patient age, previous smoking, or previous sternotomy, recovery in these complex cases could be improved through efforts to reduce rates of prolonged ventilator support, raise public awareness about smoking, train cardiac surgeons in AVSRR, and use blood-conservation strategies when appropriate.

\section{Webcast}

You can watch a Webcast of this AATS meeting presentation by going to: http://webcast.aats.org/2016/Video/ Monday/05-16-16_Hall_E_1535_Preventza-800.mp4.

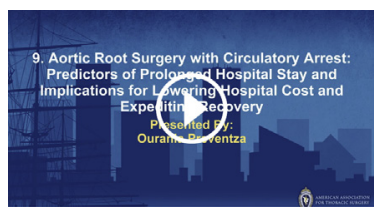

\section{Conflict of Interest Statement}

J.S.C. participates in clinical research trials conducted by Glaxo Smith Kline, Edwards Lifesciences, and Bolton Medical; consults for, receives royalties and a departmental educational grant from, and participates in clinical trials for Vascutek Terumo; and consults and participates in clinical trials for Medtronic, Inc, and W. L. Gore \& Associates. O.P. consults for Medtronic, Inc, and W. L. Gore \& Associates, and she has received travel expenses from Cook Medical, Inc. All other authors have nothing to disclose with regard to commercial support.

\section{References}

1. Bavaria JE, Desai N, Szeto WY, Komlo C, Rhode T, Wallen T, et al. Valve-sparing root reimplantation and leaflet repair in a bicuspid aortic valve: comparison with the 3-cusp David procedure. J Thorac Cardiovasc Surg. 2015;149:S22-8.

2. Cameron DE, Alejo DE, Patel ND, Nwakanma LU, Weiss ES, Vricella LA, et al. Aortic root replacement in 372 Marfan patients: evolution of operative repair over 30 years. Ann Thorac Surg. 2009;87:1344-9; discussion 1349-50.

3. Dapunt OE, Easo J, Holzl PP, Murin P, Sudkamp M, Horst M, et al. Stentless full root bioprosthesis in surgery for complex aortic valve-ascending aortic disease: a single center experience of over 300 patients. Eur J Cardiothorac Surg. 2008;33:554-9.

4. Etz CD, von Aspern K, Girrbach FF, Battellini RR, Akhavuz O, Leontyev S, et al. Long-term survival after composite mechanical aortic root replacement: a consecutive series of 448 cases. J Thorac Cardiovasc Surg. 2013;145:S41-7.

5. Meszaros K, Liniger S, Czerny M, Stanger O, Reineke D, Englberger L, et al. Mid-term results of aortic root replacement using a self-assembled biological composite graft. Interact Cardiovasc Thorac Surg. 2014;19:584-9.

6. Price J, Magruder JT, Young A, Grimm JC, Patel ND, Alejo D, et al. Long-term outcomes of aortic root operations for Marfan syndrome: a comparison of Bentall versus aortic valve-sparing procedures. J Thorac Cardiovasc Surg. 2016;151:330-8.

7. Soppa G, Abdulkareem N, Smelt J, Van Besouw JP, Jahangiri M. High-volume practice by a single specialized team reduces mortality and morbidity of elective and urgent aortic root replacement. Aorta (Stamford). 2013;1:40-4.

8. Svensson LG, Pillai ST, Rajeswaran J, Desai MY, Griffin B, Grimm R, et al. Long-term survival, valve durability, and reoperation for 4 aortic root procedures combined with ascending aorta replacement. J Thorac Cardiovasc Surg. 2016; 151:764-74.e4.

9. Zehr KJ, Orszulak TA, Mullany CJ, Matloobi A, Daly RC, Dearani JA, et al. Surgery for aneurysms of the aortic root: a 30-year experience. Circulation. 2004 110:1364-71.

10. Preventza O, Garcia A, Tuluca A, Henry M, Cooley DA, Simpson K, et al Innominate artery cannulation for proximal aortic surgery: outcomes and neurological events in 263 patients. Eur J Cardiothorac Surg. 2015;48:937-42; discussion 942.

11. Coselli JS, Hughes MS, Green SY, Price MD, Zarda S, de la Cruz KI, et al. Valvesparing aortic root replacement: early and midterm outcomes in 83 patients. Ann Thorac Surg. 2014;97:1267-73; discussion 1273-4.

12. Ergin MA, Spielvogel D, Apaydin A, Lansman SL, McCullough JN, Galla JD, et al. Surgical treatment of the dilated ascending aorta: when and how? Ann Thorac Surg. 1999;67:1834-9; discussion 1853-6.

13. Gott VL, Greene PS, Alejo DE, Cameron DE, Naftel DC, Miller DC, et al Replacement of the aortic root in patients with Marfan's syndrome. N Engl J Med. 1999;340:1307-13.

14. Malaisrie SC, Duncan BF, Mehta CK, Badiwala MV, Rinewalt D, Kruse J, et al. The addition of hemiarch replacement to aortic root surgery does not affect safety. J Thorac Cardiovasc Surg. 2015;150:118-24.e2.

15. Gaudino M, Lau C, Munjal M, Avgerinos D, Girardi LN. Contemporary outcomes of surgery for aortic root aneurysms: a propensity-matched comparison of valve-sparing and composite valve graft replacement. J Thorac Cardiovasc Surg. 2015;150:1120-9.e1.

16. Stamou SC, Williams ML, Gunn TM, Hagberg RC, Lobdell KW, Kouchoukos NT Aortic root surgery in the United States: a report from the Society of Thoracic Surgeons database. J Thorac Cardiovasc Surg. 2015;149:116-22.e4.

17. Williams JB, Peterson ED, Zhao Y, O'Brien SM, Andersen ND, Miller DC, et al Contemporary results for proximal aortic replacement in North America. J Am Coll Cardiol. 2012;60:1156-62.

18. Etz CD, Plestis KA, Homann TM, Bodian CA, Di Luozzo G, Spielvogel D, et al Reoperative aortic root and transverse arch procedures: a comparison with contemporaneous primary operations. J Thorac Cardiovasc Surg. 2008;136: 860-7. 867.e1-3.

19. Chu MW, Losenno KL, Moore K, Berta D, Hewitt J, Ralley F. Blood conservation strategies reduce the need for transfusions in ascending and aortic arch surgery. Perfusion. 2013;28:315-21.

20. Smith D, Grossi EA, Balsam LB, Ursomanno P, Rabinovich A, Galloway AC et al. The impact of a blood conservation program in complex aortic surgery. Aorta (Stamford). 2013;1:219-26.

21. Yaffee DW, DeAnda A, Ngai JY, Ursomanno PA, Rabinovich AE, Ward AF, et al Blood conservation strategies can be applied safely to high-risk complex aortic surgery. J Cardiothorac Vasc Anesth. 2015;29:703-9.

22. David TE, Feindel CM, David CM, Manlhiot C. A quarter of a century of experience with aortic valve-sparing operations. J Thorac Cardiovasc Surg. 2014;148: 872-9; discussion 879-80. 
Key Words: postoperative hospital stay, circulatory arrest, aortic root surgery, intraoperative packed red blood cell transfusion, and aortic valve-sparing root replacement

\section{Discussion}

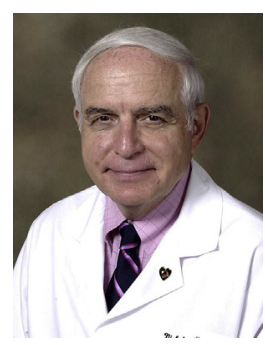

Dr N. Kouchoukos (St. Louis, Mo). Drs Preventza, Coselli, and their colleagues have identified predictors of prolonged hospital stay after aortic root replacement that is combined with ascending aortic and arch surgery requiring circulatory arrest in an attempt to determine what interventions or modifications of care, if any, could be implemented to reduce LOS and overall hospital costs for these extensive procedures.

The significant predictors, by multivariate analysis when stratified by LOS, were age, re-do sternotomy, smoking history, intraoperative red cell transfusion, and ventilatory support for more than 24 hours. These variables also predicted prolonged LOS in several subgroup analyses, including the subgroup that excluded patients who underwent TAR. In the analysis that used LOS as a continuous variable, however, several other variables significantly affecting LOS were identified and included TAR, reoperation for bleeding, transfusion of fresh-frozen plasma, and need for tracheostomy.

Dr Preventza, you suggest that recovery, LOS, and cost could be improved by reducing the duration of ventilatory support, use of blood-conservation strategies, raising public awareness of smoking, and training cardiac surgeons in valve-sparing techniques. Have you, as a result of your study, implemented protocols to promote early extubation and blood conservation or to reduce the frequency of reoperations for bleeding, and if so, have you noted any improvements?

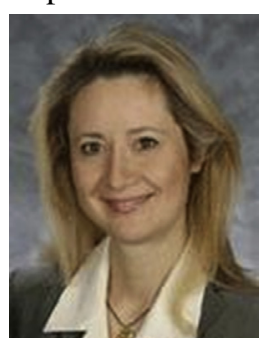

Dr Preventza. Thank you, Dr Kouchoukos. First of all, the limitation of our study is the fact that it is a retrospective study and has an inherent bias. Nevertheless, the main reason why we performed the study was to see as clinicians and as cardiac surgeons what we can do differentlyintraoperatively, preoperatively, or postoperatively-to help the patients who had an aortic root repair or replacement in conjunction with circulatory arrest to reduce LOS. Of course, blood-conservation strategies have been shown for coronary artery bypass that have improved outcomes. We are in the process right now (with anesthesia colleagues, the blood bank, and perfusionists) of forming a multidisciplinary team to determine trigger factors for transfusions and to identify other strategies that we can use to reduce blood transfusions.

What we have seen (but haven't studied enough yet) has to do with the use of autologous blood transfusions. The anesthesia colleagues take autologous blood before sternotomy, and we transfuse this blood postoperatively after the protamine and the cell saver. We have noticed that these patients are receiving fewer blood transfusions. We are in the process of trying to implement this strategy in some protocols.

Dr Kouchoukos. You suggest that training surgeons to do more valve-sparing operations might improve outcomes. There are several large studies of root replacement from Cleveland and also from New York that have shown greater rates of reoperation after valve-sparing procedures in comparison to root replacement. Do you believe this is a viable strategy?

Dr Preventza. We strongly believe that is a viable strategy. Dr Svensson and colleagues from the Cleveland Clinic already have shown that the valve-sparing operation is associated with a decreased LOS, and we believe that this is a good operation. It is an operation that the young surgeon should be trained to do and also should be reproducible. The whole idea is to help the patients and train younger surgeons.

Dr Kouchoukos. Finally, the median circulatory arrest time was 19 minutes, and this included the 26 patients who had TAR, and this was by far a very small minority. Have you considered using simple hypothermic circulatory arrest with moderate hypothermia rather than ACP for those patients who require only hemiarch replacement, which, as mentioned, were the overwhelming majority? This could conceivably simplify the procedure and possibly reduce the prevalence of some of the variables that you identified as contributing to increased morbidity, cost and LOS.

Dr Preventza. That is an excellent question. It is our strategy to use ACP and proceed with the repair under moderate hypothermia to protect the brain. Your recommendation could also be valuable and well taken.

\section{Dr Kouchoukos. Thank you.}

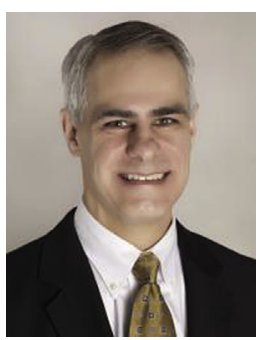

Dr S. LeMaire (Houston, Tex). Could you comment on the strategy for myocardial protection during these operations, which often have substantial myocardial ischemic times? Is there anything special about the strategy for protecting the heart?

Dr Preventza. Our strategy is to use antegrade and retrograde cardioplegia for myocardial protection. 